\title{
The impact of the public and private waste sector on solid waste management practices in small Welsh hotels
}

\author{
H. Radwan, E. Jones \& D. Minoli \\ Cardiff School of Management, University of Wales Institute, Cardiff, UK
}

\begin{abstract}
Landfill dominates Welsh solid waste management (SWM) strategies despite harmful impacts on the environment. Reducing solid waste for landfill is therefore an imperative. Although small hotels individually produce small quantities of solid waste, collectively the volume is significant with much going to landfill although the waste hierarchy offers more sustainable alternatives that small hotels could use. Small hotels are businesses and legally required to make appropriate arrangements for SWM - either through the public or private sector. Earlier research in Wales emphasises economic forces in motivating small hotels SWM practices. Welsh local authorities play a major role in SWM. They are more committed to sustainable SWM practices as they are under pressure to meet the recycling and composting targets in Wales' Waste Strategy 2002. The private sector also plays a significant role in SWM but is not under pressure to meet targets and is more concerned with waste collection and landfilling. Both the public and private sector are critical to offering more sustainable SWM strategies for small hotels. This paper explores the support available to small hotels for SWM. A qualitative approach is used to develop a rich picture of the issues being investigated. Semi-structured interviews with waste management officers and private waste companies within a Welsh local authority show that neither provides appropriate support to commercial businesses, particularly towards waste minimisation and composting. The research concludes a fundamental review of SWM practices is needed to offer more sustainable SWM strategies to small hotels.
\end{abstract}

Key words: solid waste, disposal, landfill, recycling, composting, sustainable, landfill tax, partnership, public sector, private sector. 


\section{Introduction}

The hospitality industry in Wales is dominated with small/family run businesses, e.g. small hotels, guest houses and bed and breakfast operations (B\&Bs). Many businesses regard their environmental responsibilities as secondary and have no intention of undertaking any action to reduce their impacts on the environment [1]. Hotel operations, such as waste disposal, can significantly impact on the environment and contribute to the emergence of some local and global problems if not effectively managed [2].

Solid waste is generated as a result of inappropriate production and/or consumption and places a huge cost (economic and environmental) on the community through its collection, handling and disposal [3]. In the UK, solid waste generation is increasing at a rate of $3 \%$ per year which is higher than GDP and faster than most other European countries [4]. Although concern about SWM has increased since 1988 [5], Wales still has significant waste problems undertakes landfill as a primary waste disposal route and attains very poor recycling rates [6]. In fact, neither the public or private waste sectors in Wales will be able to continue using landfill in the long-term as sites become more restricted [3].

The Centre for Business, Relationships, Accountability, Sustainability and Society (BRASS) [7] reported various drawbacks of the UK's SWM industry compared to other European countries: lack of integration between stakeholders and alternative SWM strategies and inadequate public sector infrastructure to support businesses in implementing sustainable SWM practices. The UK government is under pressure to develop an integrated approach to SWM involving the public and private sectors, businesses and local communities to phase out landfill [4]. Wright [8] added that local authorities should pay more attention to the waste produced by the commercial/industrial sectors and develop initiatives to help businesses reduce waste at source.

This paper will explore SWM practices undertaken by the public and private waste sectors and identify how far they can support small hotels to manage their solid waste more sustainably.

\section{Literature review}

Solid waste produced by small businesses is a major issue in the UK [7] with small businesses generating about $60 \%$ of commercial waste [9]. Solid waste is one of the most adverse impacts of small hotels on the environment and every hotel guest can typically produce $1 \mathrm{~kg}$ of waste a day which translates into mountains of waste annually [10], much of which goes to landfill. However, up to $60 \%$ of this waste could be reused, recycled and composted [10] reducing disposal costs - Wright [9] indicated that UK businesses spend about 4\% of their turnover on SWM annually. Additionally, there are hidden costs to solid waste production - i.e. the cost of raw materials, energy and staff [11].

Overall, SWM in Wales is dominated by landfill as the major disposal route. In an attempt to encourage the implementation of other sustainable alternatives, 
the Welsh Assembly Government (WAG) developed an integrated approach to SWM across Wales and published a national waste strategy [12]. However, WAG alone will not be able to reach the desired changes. It needs all stakeholders to reconsider their SWM practices [12]. The UK government introduced a national programme, Envirowise, to specifically support small and medium-sized enterprises (SMEs) waste reduction. The programme provides various services to encourage waste minimisation, e.g. free publications, telephone advice and workshops $[8,13]$.

In the UK, the waste management sector is regulated by the Environmental Protection Act (EPA) 1990 [14]. All waste producers must comply with section 34 of the Act - 'Duty of Care' - which requires the use of authorised waste carriers for waste handling [15]. The Environment Agency controls public and private waste operators through a licensing system [11].

The waste hierarchy [16] identifies waste management preferences for handling different waste streams. It is essential the public and private sector use it to guide their SWM strategies emphasising more sustainable options and phasing out landfill [17]. Both sectors should provide a range of facilities and services implementing the preferred options in the waste hierarchy and should educate small hotels on reducing waste and/or cutting it at source, e.g. through green purchasing practices. Moreover, waste carriers should support recycling and composting by commercial businesses, e.g. through bins/bags to separate their waste.

All UK local authorities are required to develop their own SWM strategies and encourage resource recovery initiatives [18]. Timilsina [19] asserts the duty of local authorities to support appropriate SWM by all community sectors, e.g. with schemes for recycling and composting waste. Furthermore, local authorities should work in partnership to achieve their waste minimisation targets [20]. Gray [21] indicated that some UK local authorities have reduced the amounts of waste going to landfill through more SWM practices. Adams [22] reported a range of barriers encountered many Welsh local authorities in providing a comprehensive recycling system including: lack of financial and personnel resources; public apathy; volatility of markets for recyclables.

Understanding businesses' circumstances is crucial to effective commercial recycling systems. The local authority should explore business needs and develop appropriate strategies to encourage their participation, regardless of the type and size, in recycling programmes [23]. Some local authorities in the United States (e.g. San Diego County) have legally mandated recycling although the law only applies to larger businesses [24, 25]. Apotheker [25] identified various ways in which local authorities could enhance small business recycling cluster collections; charging for commercial waste collection; developing markets for recycled materials; raising awareness of the benefits of recycling programmes; cooperation with the private waste sector.

Similarly the private sector has played a significant role in the UK waste management industry [26]. Some larger waste companies, e.g. Biffa, have shown a greater commitment to diverting waste from landfill and implementing more sustainable approaches, e.g. recycling [15]. Cointreau-Levine [27] identified 
several advantages of private-sector SWM: lower prices to create competitive advantage and satisfy customer needs; greater flexibility and reliability; and fewer procedural constraints. Furthermore the private sector is more innovative in service quality enhancement working continually towards developing technical and organisational processes [28].

Ligon et al. [29] identified two types of waste disposal contracts linking them to waste minimisation approaches: traditional and Resource Management (RM) contracts. Traditional contracts focus on quantities of waste produced and put waste producers and contractors in conflict - producers want to reduce waste and reduce disposal costs; contractors want to collect more waste to make more money. RM contracts focus on services provided not the amount of waste aligning agendas of waste producers and contractors. Waste contractors can help producers reduce and recover waste and charge for support services. Nowadays many waste contractors are changing to RM contracts and diversifying services and building long-term relationships with customers [29].

\section{Methodology}

A qualitative research approach using a case study was used to explore key issues related to public and private-sector SWM in a Welsh local authority and the impact of waste carriers on SWM practices of small hotels. This approach enabled the researcher to understand the rationale behind the actions rather than just find out what these actions are and gave the opportunity to focus holistically rather than dealing with isolated factors.

Data was collected using semi-structured interviews to get a deeper understanding of the issues. Four interviews were conducted with the local authority's waste management officers and two with the executives of private waste companies, via a convenience sampling procedure. A range of issues were discussed during the interviews including: the current waste management options undertaken by the public and private waste sectors to handle commercial waste, the constraints on the waste carriers in recycling waste and the opportunities for the local authority and the private waste sector to work in partnership to reduce and recycle commercial waste. All interviews were recorded, transcribed and analysed, through a "constant comparative method" [30], while the study's design and its findings were internally validated.

\section{Results and discussion}

\subsection{Waste management}

The local authority had provided a commercial recycling system for commercial businesses since January 2006 offering three different schemes - cardboard, glass and mixed recycling bag. They had organised brochures to make businesses aware of the importance of recycling and how to do it. Interestingly, the council planned to offer the service to any business wanting it regardless of size, location or type of materials produced (except hazardous waste). As one local authority 
officer said: 'We have not got a specific target in terms of number of businesses. We want to push it to as many businesses as we can get it to'.

The mixed recycling bag is considered appropriate for small hotels to recycle their waste. Businesses are not required to separate their waste which eliminates many of the difficulties associated with the segregation - time, cost and space. Instead, all waste materials are collected mixed in one bag and then sorted out in the council's Material Recycling Facility (MRF).

The local authority had not actively explored composting. They had a programme to support in-house composting by businesses providing informal advice on request but did not have facilities for composting food waste. As one local authority officer said: 'It is one step at a time for us. Basically, we are developing a business'.

The private waste sector had two options for dealing with commercial waste: recycling (through two different schemes clean waste and mixed loads) and landfilling. They did not offer composting or incineration in Wales although one respondent claimed they were offered in other areas. In the clean waste scheme customers were offered discounts for segregating waste with two collection services (one for general waste and one for recyclables). In the mixed load scheme the company collected mixed waste and separated it in their MRF. As one private sector participant commented:

We recycle $50 \%$ of our waste and the other $50 \%$ is landfilled. We do not own a landfill site but we deal with one up in Gloucester because it is cheaper to bin.

\subsection{Working with businesses to reduce waste}

Although WAG set waste minimisation targets for all local authorities, the council did not have plans to work with businesses to reduce waste. They directed businesses, if asked, to specific organisations (e.g. Arena Network, Envirowise) for advice. The local authority considered their waste minimisation targets as secondary objectives - their primary targets were to meet the recycling rates: 'No, we signpost businesses to other organisations that can help them with that, e.g. Envirowise. We don't have the resources to do that work for businesses'.

BRASS [31] similarly indicated that most local authorities were not really committed to reducing commercial waste. The private waste contractors were focused on collecting and landfilling ever-larger quantities of waste. As one private sector interviewee asserted it would not be in their interests to help businesses reduce their waste: 'Well, that is not our objective. We are here to make money not to help them reduce their waste'.

However, the larger private contractor had an advisory team and specialists to work with businesses, if they were asked, to help them reduce waste. One participant indicated that his company normally provided site visits to identify waste streams and advise on the best ways to reduce costs, e.g. through reuse and recycling. 


\subsection{Constraints to recycling of small businesses' waste}

The public and private-sector interviews identified a range of obstacles to recycling commercial waste. All interviewees agreed that cost was the most significant obstacle to recycling resulting in limited resources for enhancing SWM practices with insufficient staff to deal with the various activities - e.g. education and enforcement. Cohen [4] indicated similar problems in recycling, e.g. lack of resources and inability to find markets for recyclables. As one local authority officer commented - 'It is a cost and resource issue'.

Waste contamination was another critical issue. Most respondents stressed the importance of ensuring waste was not contaminated with food to make recycling a viable option. Moreover, business location was considered a barrier to collecting recyclables from small businesses. Many small hotels were operating in former domestic premises so that the council had restricted access due to the size of the roads. The local authority had a small number of vehicles for commercial waste collection posing problems for the frequency of collections. However, one local authority officer suggested that:

The thing that they might be able to do is rather than having individual waste collection, having a communal waste collection. If you have 3 or 4 closely located premises you could just do one collection for those.

For the private sector, all participants identified two main challenges facing them in recycling: the cost of recycling (it was too expensive for most waste companies to operate MRF to sort waste) and the lack of markets for recyclable materials. As one private-sector interviewee commented:

Capital funding, buying the machinery to do the job, at the end of the day whether it is profitable or not...it is difficult to find a home for some of the recycled materials because not everybody wants it.

\subsection{Main drivers to consider sustainable waste practices}

The local authority officers identified four key issues for encouraging small hotels' owners/managers to recycle: cost; convenience; awareness; and legislation. All agreed that cost would be the most significant issue. UK landfill taxes were much lower than other European countries, e.g. Germany. At the time of the study it was only $20 \%$ cheaper to recycle than dispose to landfill. One officer indicated that small hotels would be unlikely to recycle to save $13 \mathrm{p}$ per bag but that this gap would increase as landfill taxes increased.

I think cost is the most important thing. If you can prove that it will save the business money, they probably will do it. The second thing is convenience; if it is easy to do they will do it. Thirdly I think that's really important part to their product. It makes a good business sense.

Martin and Scott [32] similarly commented that current landfill taxes have failed to significantly influence small business waste management strategies. Currently, the local authority charged businesses either by the bag or by the bin. One officer indicated that they might charge in the future by weight and this would incentivize businesses to reduce and recycle waste. Fullerton and 
Kinnaman [33] assert the effectiveness of "pay as you throw" in encouraging waste reduction.

Presently, local authorities could only use legislation to monitor appropriate waste disposal by businesses through licensed waste carriers. Most officers interviewed felt that it was difficult to set legislation for recycling, particularly at the level of small businesses. Interestingly, the local authority could use section 47 of the EPA 1990 to enforce recycling. However, by doing that businesses, particularly those who did not want to recycle, would shift to the private sector which is not under the same pressure to recycle. For recycling legislation to be effective both the public and private sectors must be included. As a local authority officer pointed out:

It might be with Tesco's but not with smaller businesses...There is legislation for the local authority as I said section 47 in the EPA. We can say to someone you got to put your material in that container. If we enforce it all they do is go to Biffa or Violia. It makes no difference to them. It is all money driven.

Similarly, the private sector showed that landfill tax and legislation were the most effective tools that could be used to drive the waste management sector towards sustainability. One private sector operator suggested that it would be more profitable for the private sector to recycle than landfill as the company would not only get paid for collection of the waste but also would earn money from selling recyclables. He added that his company operated a large MRF and produced new products, as explained below:

We do car tyres. We cut them up, take the wire out and we use the rubber chip for horse arenas for training race horses, it gives a bounce. We also send lots of tyres to cement kilns for burning as a fuel rather than burning coal or oil. The calorific value of tyres is far higher than coal. We take out wood. We fragment it up and that goes to chip board factories to make kitchen, desks and also burning it for electricity.

\subsection{Working with the private waste sector}

All the local authority interviewees indicated that it was very difficult to work with the private sector to reduce landfill because they had different targets. The private sector wanted to collect and landfill large quantities of waste to make more money and assisting businesses to reduce waste conflicted with these objectives whereas the public sector was more committed to divert waste from landfill. Most interviewees felt that public and private sector objectives were incompatible. However, Gray [21] and CRN [34] indicated that many local authorities in the UK were actively working in partnership with the private sector to implement sustainable waste practices.

The private sector is a massive problem. The private contractors can pick up whatever they want and take it to landfill, it does not matter to them; all they want is the money and to please their shareholders. They have not got the same obligation as the local authority to pull it out from landfill, totally different ball game. 
Surprisingly, the two private sector respondents indicated that they worked closely with a number of local authorities to meet recycling and composting targets. One participant was in partnership with Cardiff, Rhondda and Vale of Glamorgan councils to support recycling as these councils did not have facilities to sort rubbish and described such partnerships as a valuable financially and environmentally. The second participant was negative about working with the local authority arguing that they had very different philosophies:

We did composting for the local council ... We are on a different levels. They are in the public sector where profit does not count. I have to make a profit. The council philosophy is to do it by the book to fill their political and regulatory duties.

\section{Conclusion}

The role of public and private-sector waste carriers is critical in helping small hotels manage solid waste effectively. The waste management strategies of both public and private sectors need to be revised to encourage more sustainable alternatives. The findings show the local authority is more committed to recycling than private operators who are more concerned with waste collection and landfilling. Thus, the government has two options to promote recycling: increasing landfill tax and enacting legislation for recycling.

The study identifies a range of obstacles facing the public and private sectors in undertaking recycling as a SWM strategy. Among these are: the huge costs needed to run a MRF and the lack of recyclable markets. WAG should consider more funding for local authority waste management activities and developing markets for recycled materials. In turn, the local authority should consider developing partnerships with the private waste sector to help them recycle and compost their waste.

Although food waste constituted the largest waste stream from small hotels the carriers had no options other than landfilling. Neither the public nor private sectors had composting systems for organic waste. This emphasises the need for investment in composting plants and encouraging small hotel operators to separate their food waste for composting.

The findings also reveal that the local authority had undertaken little action to meet waste minimisation targets. The private waste operators believed that helping businesses to reduce and recycle their waste contradicted their business objectives. The government must develop a business model which encourages all stakeholders to work enthusiastically to reduce and recycle waste, e.g. providing site visits, advice and free publications. RM contracts would be an ideal way to motivate waste carriers to consider this issue.

\section{References}

[1] Goodall, B. Environmental Auditing: A Tool for Assessing The Environmental Performance of Tourism Firms, Geographical Journal, 161(1), pp. 29-37, 1995. 
[2] Chavan, M. An Appraisal of Environmental Management Systems A Competitive Advantage for Small Businesses, Management of Environmental Quality: An International Journal, 16(5), pp. 444-463, 2005.

[3] Sarkis, J. and Dijkshoorn, J. An Exploratory Evaluation of Economic and Environmental Efficiency of Solid Waste Management in Welsh Small and Medium-sized Enterprises, Working Paper Series No. 31, (BRASS), ISBN 1904393675 (Web), 2005.

[4] Cohen, C. Response to E-Politix Forum Brief on Waste Management: Controlling The UK Waste Mountain, http://www.brass.cf. ac.uk /uploads/caepolitixcc0303.pdf, accessed 20/06/2006.

[5] Price, J. Implementation of Household Waste Recycling - Top Down or Bottom up Approach? Journal of Waste Management and Resource Recovery, 3(3), pp. 127-134, 1996.

[6] Environment Agency and CCW A Living and Working Environment for Wales: The State of The Environment, 2003. In Jenkins, V. Developing a Distinctive Approach to Environmental Law in Wales, UKELA Seminar, Cardiff, 13 June 2006.

[7] The Centre for Business Relationships, Accountability, Sustainability and Society (BRASS) Future of Waste Management: Moving up The Waste Hierarchy, BRASS, 2003, http://www.brass.cf.ac.uk/ uploads/conresponse EFRAJan2003.pdf., accessed 15/06/2006.

[8] Wright, L. local Government Waste Minimisation Initiatives \& Small and Medium Sized Enterprises, http://www.mwhglobal.co.nz/files /WMINZ02-LW.pdf., accessed 15/06/2006.

[9] Environment Agency Business Survey Reveals Lack of Environmental Awareness, Environment Action, 37, April, 2003.

[10] IHEI Hotels Care: Community Action and Responsibility for The Environment, International Hotel Environmental Initiative, UK, 2002.

[11] DETR Waste Strategy 2000 England and Wales Part 2, London, UK, 2000.

[12] Cohen, C. The Challenge of Developing Markets for Recyclates in Wales, http://www.brass.cf.ac.uk/uploads/cawasterecyclates cc0703.pdf, accessed 15/06/2006.

[13] Phillips, P.S., Clarkson, P. and Barnes, N.J. A UK County Sustainable Waste Management Program, International Journal of Environment and Sustainable Development, 1 (1), pp. 2-19, 2002.

[14] Read, A.D., Phillips, P. and Robinson, G. Landfill as a Future Waste Management Option in England: The View of Landfill Operators, The Geographical Journal, 164 (1), pp. 55-66, 1998.

[15] Webster, K. Environmental Management in The Hospitality Industry: A Guide for Students and Mangers, London, Cassell, 2000.

[16] Read, A.D., Phillips, P.S. and Murphy, A. English County Councils and their Agenda for Waste Minimisation, Resources, Conservation and Recycling, 20 (4), pp. 277-294, 1997.

[17] House of Commons Sustainable Waste Management: Environment, Transport and Regional Affairs Committee, Six Report, 1, HMSO, London, 1998. 
[18] Hams, T., Jacobs, M., Levett, R., Lusser, H., Morphet, J., and Taylor, D. Greening your Local Authority, Longmans, Harlow, 1994.

[19] Timilsina, B.P. Public and Private Sector Involvement in Municipal Solid waste Management: An Overview of Strategy, Policy and Practices, Journal of The Environment, 6(7), pp. 68-77, 2001.

[20] DETR Guidance on Municipal Waste Management Strategies, London: HMSO, 2001.

[21] Gray, J.M. Environment, policy and Municipal Waste Management in the UK, Transactions IBG, 22(1), pp. 69-90, 1997.

[22] Adams, M. Consumer Waste Recycling Provision and Quality of Service in Wales: A Welsh Consumer Council Report, Cardiff, The Welsh Consumer Council, pp. 1-84, 1998.

[23] Stevens, B. and Kusterer, T. Targeting Business Categories, BioCycle, 36(7), pp. 61-62, 1995.

[24] Oskamp, S., Harrington, M.J., Edwards, T.C., Sherwood, D.L., Okuda, S.M. and Swanson, D.C. Factors Influencing Household Recycling Behaviour, Environment and Behaviour, 23(4), pp. 494-519, 1991.

[25] Apotheker, S. Making The Big Jump in Commercial Recycling, One Small Business at a Time, Resource Recycling, 14, 16-26, 1995.

[26] Reamer, S. Contract Service Firms in Local Authorities: Evolving Geographies of Activity. Regional Studies, 33(2), pp. 121-130, 1999.

[27] Cointreau-Levine, S. Part II: Guidance Note. In Cointreau-Levine, S. and Coad, A. Private Sector Participation in Municipal Solid Waste Management: Guidance Pack. St. Gallen, Switzerland: Swiss Centre for Development Cooperation in Technology and Management (SKAT), 2000.

[28] Bel, G. and Miralles, A. Factors Influencing The Privatisation of Urban Solid Waste Collection in Spain, Urban Studies, 40(7), pp. 1323-1334, 2003.

[29] Ligon, P., Mishra, P.N. and Votta, T. Waste Service Providers Become Resource Mangers, Journal of Composting \& Organics Recycling, p. 51, April 2000, http://www.jgpress.com/BCArticles/2000/040051B.html, accessed 28/7/2006.

[30] Glaser, B. Theoretical Sensitivity: Advances in The Methodology of Grounded Theory, Mill Valley, CA: Sociology Press, 1978.

[31] BRASS Consultation on The Review of England's Waste Strategy, http://www.brass.cf.ac.uk/uploads/Waste_Strategy_Respons.pd, accessed $15 / 06 / 2006$.

[32] Martin, A. and Scott, I. The Effectiveness of The UK Landfill Tax, Journal of Environmental Planning and Management, 46(5), pp. 673-689, 2003.

[33] Fullerton, D. and Kinnaman, T.C. Household Responses to Pricing Garbage by The Bag, The American Economic Review, 86(4), pp. 971-984, 1996.

[34] CRN (Community Recycling Network) Working in Partnership with Local Authorities, http:/www.crn.org.uk/publications/research/ info3.shtml. accessed 21/11/2006 